\title{
Cre-loxP recombination vectors for promoter studies
}

\author{
Nina Pedersen \\ Department of Radiation Biology \\ Section 6321 \\ National University Hospital \\ Blegdamsvej 9, 2100 Copenhagen $\varnothing$ \\ Denmark \\ Tel: 4535456309 \\ Fax: 4535456301 \\ E-mail: nina.pedersen@rh.hosp.dk \\ Thomas Tuxen Poulsen \\ Department of Radiation Biology \\ Section 6321 \\ National University Hospital \\ Blegdamsvej 9, 2100 Copenhagen Ø \\ Denmark \\ Tel: 4535456328 \\ Fax: 4535456301 \\ E-mail: tuxen@rh.dk \\ Hans Skovgaard Poulsen* \\ Department of Radiation Biology \\ Section 6321 \\ National University Hospital \\ Blegdamsvej 9, 2100 Copenhagen Ø \\ Denmark \\ Tel: 4535456303 \\ Fax: 4535456301 \\ E-mail: hans.skovgaard.poulsen@rh.hosp.dk \\ Website: http://www.radiationbiology.dk/
}

\begin{abstract}
Financial support: National University Hospital, the Danish Cancer Society, the Danish Medical Research Council, TheDanish Cancer Research Foundation, the Erik Hørslev og Hustru Birgit Hørslevs Foundation, the Aase and Ejnar Danielsens Foundation and the A.P. Møller Foundation for the Advancement of Medical Science.
\end{abstract}

Keywords: cloning, Cre recombinase, plasmid, reporter genes, therapeutic genes.

\footnotetext{
Abbreviations: $\quad$ cDNA: complementary DNA

EGFP: enhanced green fluorescent protein

HSVTK: Herpes Simplex virus thymidine kinase

PCR: polymerase chain reaction

SNP: single nucleotide polymorphism
}

For promoter studies the cloning, subcloning and transfer to different plasmid vectors usually requires use of restriction enzymes and ligation reactions. One obstacle is the nucleotide polymorphisms of eukaryotic genomic DNA, which has the consequence that a sequence often differs from published sequences. Therefore sequencing, rigorous restriction enzyme analysis or introduction of suitable sites has to be performed prior to cloning and subcloning.

In addition, conventional methods using restriction enzymes, insert purifications and ligations is expensive and labour demanding.
We have developed a fast, efficient and inexpensive Cre recombinase-loxP based method, which allows cloning of promoter regions and subcloning of these into a variety of vectors in a restriction enzyme independent manner. We here demonstrate that expression of a number of reporter genes and a therapeutic gene from both a viral and 2 mammalian promoters cloned by this recombinase method have activities comparable to conventionally cloned plasmids.

Until recently, cloning and subcloning of DNA regions required cleavage with restriction enzymes, purification of cleaved products and ligation into vectors of interest. These

*Corresponding author 


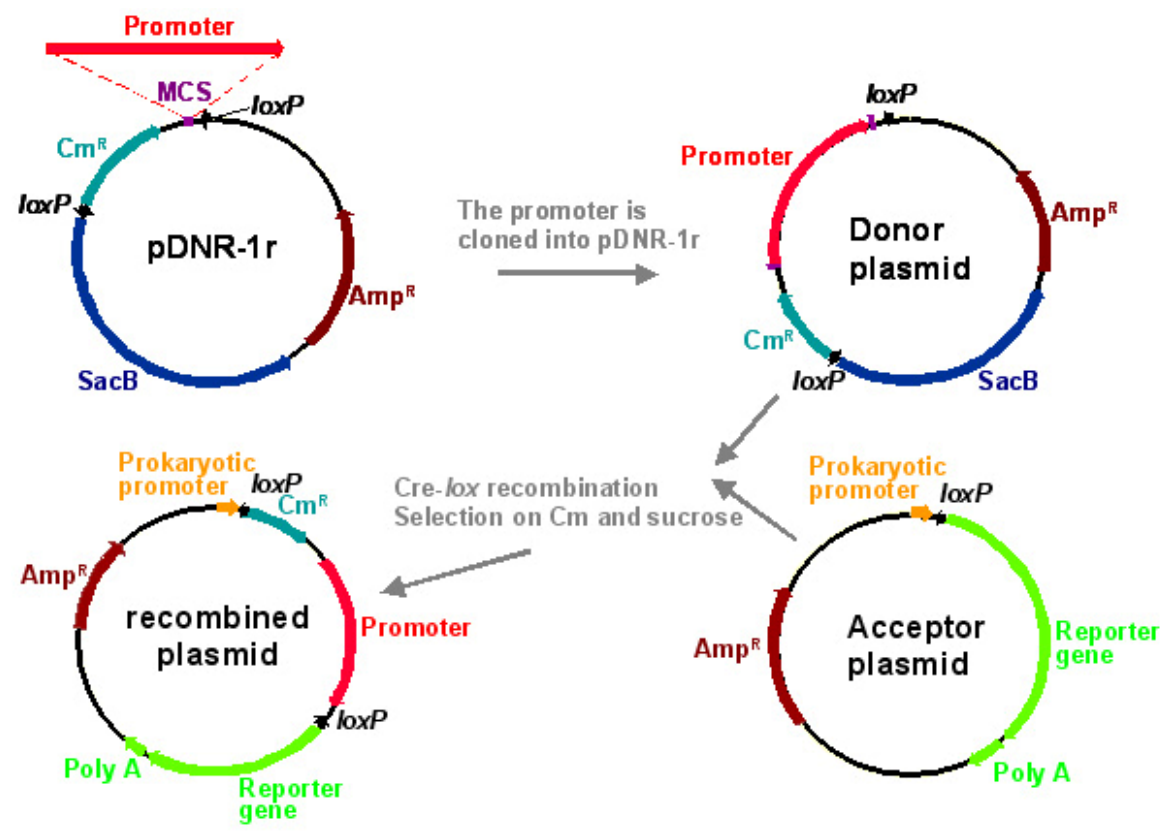

Figure 1. Flow chart of Cre-loxP based cloning of a promoter and transfer to Acceptor plasmids.

procedures are time and material consuming and therefore several novel systems have recently been developed to eliminate some of these steps. These cloning systems are based on recombinase-based methods to allow transfer of pieces of DNA from plasmid to plasmid without the use of restriction enzymes or ligase with a high efficiency and low error rate (Dutton, 2005). Several of these systems are commercially available and allow fast and simple transfer of complementary DNA (cDNAs) into a number of vectors containing various tags, fusions, promoters and selection markers. Some of the systems are based on Cre Recombinase, which was discovered in the bacteriophage P1 and which catalyses the recombination of DNA between 34 bp $\operatorname{lox} P$ sites in a sequence specific and directional manner (Hoess and Abremski, 1984). Cre recombinase can be purchased relatively cheap or produced recombinantly in bacteria (Liu et al. 1998). The Cre-loxP technology has been commonly used for excision of genes in conditional gene modifications in transgenic and knockout-mice (Sauer, 1998). Recently a system based on Cre recombinase was developed for simple cloning of promoters with various reporter genes in plants (Shigaki et al. 2005), but to date no system has been developed for mammalian promoter studies.

Promoter studies often comprise of subcloning regions of a promoter using a variety of reporter genes (e.g. luciferase for quantification, enhanced green fluorescent protein (EGFP) or $\beta$-galactosidase for localisation etc.) or therapeutic genes (e.g. the suicide genes Herpes Simplex Virus Thymidine Kinase and Cytosine Deaminase or tumor suppressor genes $\mathrm{p} 53$ and FUS1) for gene therapy purposes. Traditional subcloning strategies require the presence of a number of specific restriction sites to use for insertion of a sequence into the multiple cloning site of a vector. However, vectors with various reporter/therapeutic genes often have different (and limited) sets of restriction sites, thus requiring individual cloning strategies for each vector and promoter region. In many cases suitable sites need to be added or changed for example by polymerase chain reaction (PCR) or by generating blunt ends.

In addition to this labourious aspect, the human genome contains a number of polymorphisms - many of them consisting of single nucleotides (SNPs) which distinguish individuals. SNPs are present in average in every 1.9 kilobases (Sachidanandam et al. 2001) and are most abundant in non-coding regulatory regions (Knight, 2003). Therefore the sequence of a cloned promoter region is not always identical to the sequences reported in the different databases depending on the source of genomic DNA used. In our experience, more than $30 \%$ of the commonly used restriction sites in cloned promoter regions listed by the genomic databases are either present in higher or lower copies than the database sequence denotes. For example, 2 different sequences of the $1.7 \mathrm{~kb}$ region of the INSM1 promoter have 5 mismatches (GenBank AL161658 and HSU07172). Therefore each cloned promoter region either has to be sequenced or screened for restriction sites prior to design of a cloning/subcloning strategy. For high throughput analyses, this is extremely tedious and expensive.

We therefore developed a system, where a promoter, once cloned, can be transferred directly without the use of restriction enzymes into a number of plasmids to control expression of a variety of genes. 


\section{MATERIALS AND METHODS}

\section{Plasmids}

The generation of the following plasmids have been described elsewhere: SV40-LUC (Pedersen et al. 2006), INSM1-LUC (Breslin et al. 2003), SV40-HSV-TK (Pedersen et al. 2006).

ASCL1-LUC. The ASCL1 promoter (-623 to +63$)$ was cloned by PCR (with flanking Hind III sites) and inserted into pGL3 Basic (Promega, Mannheim, Germany) in the Hind III site.

SV40 Donor: The SV40 promoter was excised with Hind III and Sma I from pGL3 Basic and inserted into pDNR-1r (BD Biosciences, Brøndby, Denmark) in the Hind III and blunted $X b a$ I sites.

ASCL1 Donor. The ASCL1 promoter (-623 to +63$)$ was cloned by PCR (with flanking Hind III sites) using a proofreading polymerase (TaKaRa LA Taq, Cambrex Bio Science, Copenhagen, Denmark) and inserted into pDNR$1 \mathrm{r}$ in the Hind III site.

INSM1 Donor. The INSM1 promoter was excised from INSM1-LUC with Hind III and blunted Not I and ligated into Hind III and blunted $X b a$ I sites in PDNR-1r.

LUC Acceptor. The prokaryotic promoter with a 5, flanking loxP site was amplified by PCR from the Ampicillin resistance gene from pBIG (Clontech, Palo Alto, CA, USA) using the following primers: 5'AAGCTTATAACTTCGTATAGCATACATTATACGAA GTTATAGAT-CCAATATTATTGAAGCATTTATCAG

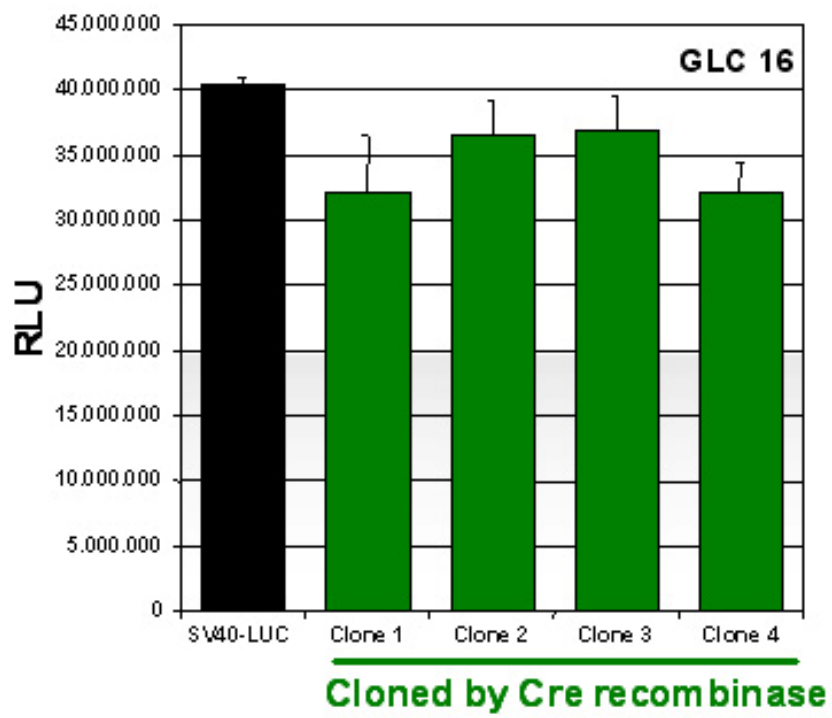

(loxP site underlined) and 5'GGTACCACGTCAGGTGGCACTTTTCG and inserted in the Kpn I and Hind III sites of pGL3 Basic.

EGFP Acceptor. The Luciferase gene was removed from LUC Acceptor with Hind III and blunted Xba I and replaced with the EGFP gene excised from pEGFP-N1 (Clontech, Palo Alto, CA, USA) with Hind III and blunted Not 1 .

DsRed Acceptor. The Luciferase gene was removed from LUC Acceptor with Hind III and blunted $X b a$ I and replaced with the DsRed1 gene excised from pDsRed1-N1 (Clontech, Palo Alto, CA, USA) with Hind III and blunted Not 1 .

$\beta$-gal Acceptor. The Luciferase gene was removed from LUC Acceptor with Hind III and blunted $X b a$ I and replaced with the $\beta$-galactosidase gene excised from pCMV-beta (Clontech, Palo Alto, CA, USA) with Hind III and blunted Xho I.

Herpes simplex virus thymidine kinase (HSVTK) Acceptor. The Luciferase gene was removed from LUC Acceptor with Hind III and blunted Xba I and replaced with the HSVTK gene excised from GRP-HSVTK (Pedersen et al. 2006) with Hind III and blunted $B g l$ II.

\section{Cre recombination}

Recombination of plasmids using Cre Recombinase was performed according to the Creator ${ }^{\mathrm{TM}}$ manual (BD Bioscience, Brøndby, Denmark). Briefly, 200 ng Donor and Acceptor plasmids are incubated with 100 ng Cre Recombinase (BD Biosciences) for $15 \mathrm{~min}$ at room

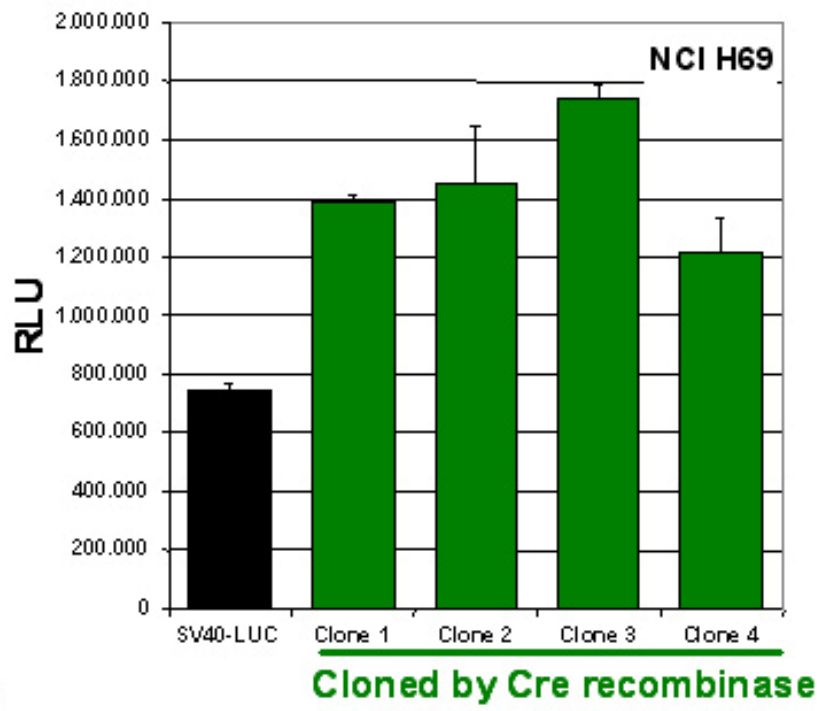

Figure 2. Comparison of luciferase expression from the SV40 promoter of a conventionally cloned plasmid and plasmids prepared using Cre-loxP based cloning. 4 individual Cre-loxP cloned plasmids and a conventionally cloned plasmid with the SV40 promoter regulating expression of luicferase were transiently transfected into 2 cell lines and luciferase activities were compared. The data shown is the mean of duplicates with S.E.M. 


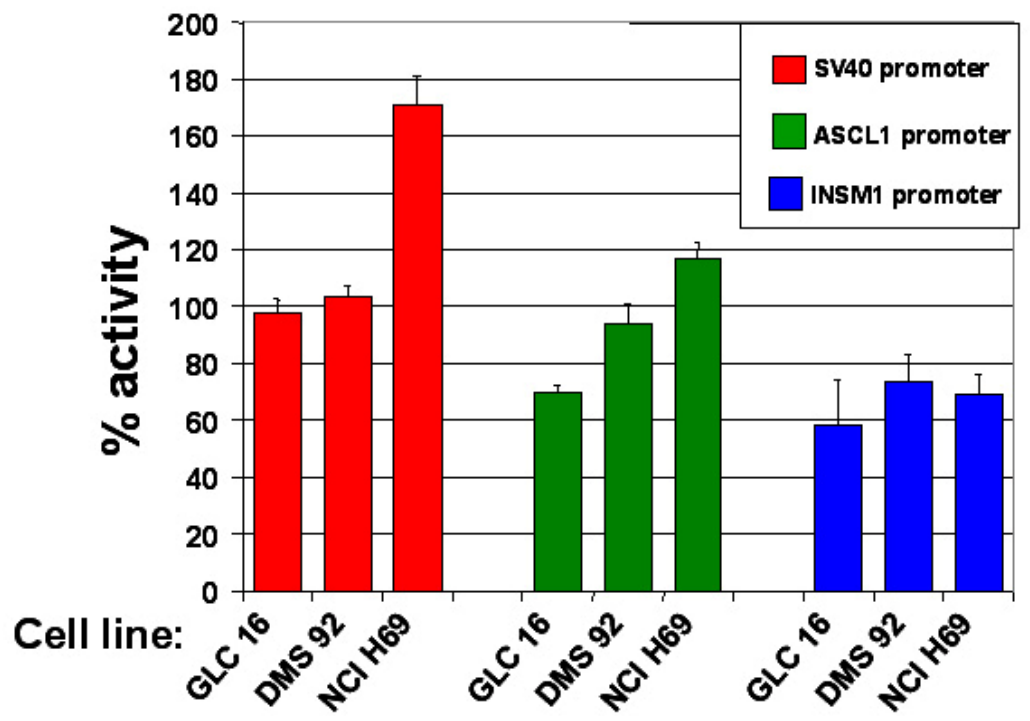

Figure 3. Percent activity of luciferase expression from Cre-loxP based cloned plasmids compared to conventionally cloned plasmids with 3 different promoters. 3 cell lines were transiently transfected and luciferase activity was measured after 2 days with the promoters indicated. Values were normalised to the expression level of the conventionally cloned plasmid with the same promoter. The data shown is the mean of 5 independent transfections in triplicate with S.E.M.

temperature in a $20 \mu \mathrm{l}$ reaction in the buffer supplied, heat inactivated at $70^{\circ} \mathrm{C}$ for $5 \mathrm{~min}$ and transformed into $\mathrm{XL}-1$ Blue (Stratagene, AH Diagnostics, Århus, Denmark). Initial selection of recombinants was performed on agar plates containing $30 \mu \mathrm{g} / \mathrm{ml}$ Chloramphenicol (Sigma-Aldrich, Brøndby, Denmark) and 7\% sucrose. After screening of colonies, the transformed bacteria were propagated with Ampicillin as the only selection marker.

\section{Cell lines}

The cell lines used were the small cell lung cancer cell lines NCI-H69, GLC 16 (suspension cells) and DMS 92 (adherent). Origin and propagation of these lines has been described in detail in Pedersen et al. 2003.

\section{Transfection assays}

Transient transfections and the luciferase assay have been described in detail in Pedersen et al. 2006. Transfection with the plasmids encoding $\beta$-galactosidase, EGFP and DsRed were performed as for luciferase, with staining with X-gal or fluorescence microscopy after 24-48 hours after transfection. Transient transfections with plasmids encoding a therapeutic gene (HSVTK), incubation with the prodrug ganciclovir (Cymevene ${ }^{\circledR}$, Roche) and an 3-[4,5dimethylthiazol-2-yl]-2.5 diphenyl tetrazolim bromide (MTT) based proliferation assay has been described in detail in Pedersen et al. 2006.

\section{RESULTS AND DISCUSSION}

The purpose of our research is to test the activities and specificities of a large number of promoter regions to identify promoter regions which can be used for transcriptionally targeted cancer gene therapy. As we test the promoter activities and specificities by several of different methods with various genes, subcloning of these many promoter regions appeared very impractical and costly by conventional methods.

We adapted the BD Creator ${ }^{\mathrm{TM}}$ system from Clontech (http://www.clontech.com/products/detail.asp?tabno=2\&cat alog_id=631615\&page $=$ all) for cloning of promoters with various genes. This system utilises a Donor vector, where the gene of interest (cDNA) is flanked by 2 loxP sequences ("floxed") and an Acceptor vector containing one loxP site and various promoters and tags. The Donor vector contains a promoterless chloramphenicol resistance gene $\left(\mathrm{Cm}^{\mathrm{R}}\right)$, whereas the Acceptor vector contains a prokaryotic promoter. These are combined at Cre recombination and enables for positive selection for recombinants on chloramphenicol. The negative selection marker gene, $\mathrm{SacB}$, in the Donor vectors is not transferred by recombination and confers bacterial death when propagated on sucrose, thereby eliminating propagation of unrecombined Donor vectors. As the Cre based recombination is sequence specific and directional, screening for orientation and sequence of the insert in the transferred vectors is unnecessary.

We reversed the Creator system to transfer promoters from Donor vectors to Acceptor vectors encoding cDNAs from various genes of interest (reporter and therapeutic genes). Promoter regions were cloned into the Donor plasmid by excision from already cloned plasmids or PCR products using restriction enzymes. Acceptor plasmids were 
a
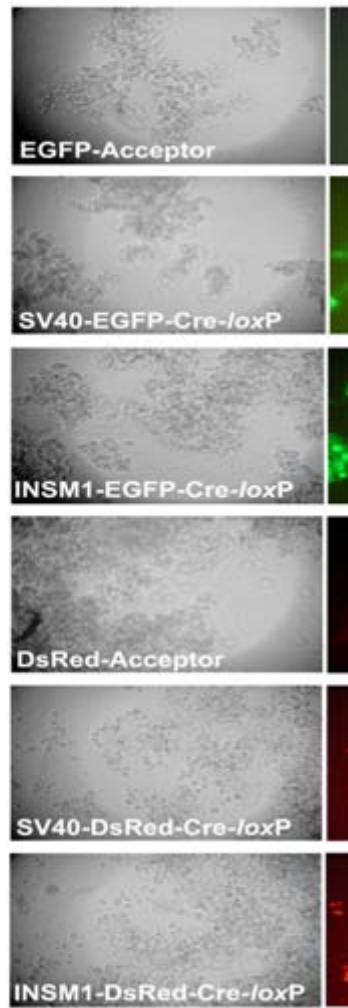
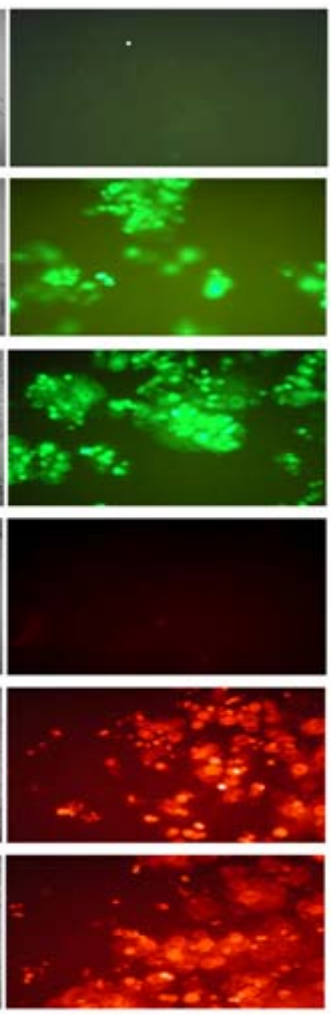

b

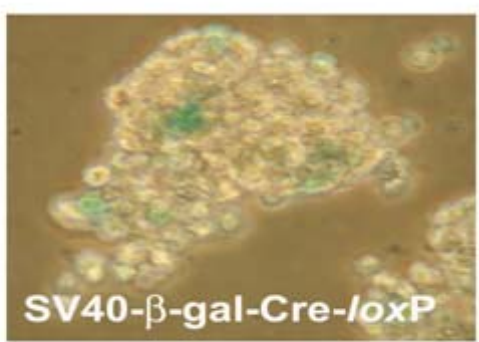

Figure 4. Expression of reporter genes from Cre-loxP cloned promoters.

(a) GLC 16 cells were transiently transfected with EGFP and DsRed Cre-loxP generated plasmids as indicated on the figure and photographed after $24 \mathrm{hrs}$. The left frames are in phase contrast and the right frames with fluorescence using $10 \mathrm{x}$ magnification.

(b) GLC 16 cells were transfected with the $\beta$-galactosidase gene regulated by the SV40 promoter cloned using the Crerecombinase system and stained with X-gal after $48 \mathrm{hrs}$.

generated by conventional cloning methods. The strategy is outlined in Figure 1.

The recombination strategy results in a $\operatorname{lox} P$ site between the promoter and gene. The $\operatorname{lox} P$ sequence contains a potential $13 \mathrm{bp}$ stem-loop structure and this secondary structure in the mRNA can interfere with the translational initiation and thereby activity of a construct (Liu et al. 1998). Also the strategy inserted the selection gene and thereby changed the backbone of the plasmid. It was therefore necessary to compare the activities of the CreloxP cloned vectors to conventionally cloned plasmids without these insertions.

To test our strategy and constructs we first generated an Acceptor vector with the reporter gene luciferase and CreloxP recombined with a Donor vector with the viral promoter SV40. Of 24 colonies picked at random 21 were correct judged by PCR and restriction enzyme analysis. In total we experienced that more than $87 \%$ of colonies tested (207 total) were correct, demonstrating the efficiency and fidelity of the system. Rather than sequencing the obtained clones, we decided to test the constructs by functionality tests, as this would reveal loss or gain of activities due to the changed backbone and/or mRNA structure.

Promoter activities were assessed using a luciferase reportergene system. Plasmids from 4 individual colonies of Cre-loxP cloned SV40-Luciferase were tested by transient transfection in 2 cell lines and activities compared to a conventionally cloned plasmid. For both cell lines all 4 clones gave approximately the same activity of luciferase (Figure 2). However, in the GLC 16 cell line this was slightly lower than for the conventionally cloned plasmid, whereas for the NCI H69 cell line it was consistently somewhat higher. The promoterless Luciferase Acceptor plasmid gave no measurable expression (data not shown).

As our interest is not in viral, but mammalian promoters, we cloned 2 human promoter regions into the Donor vector. The promoters were chosen, as they confer very high and specific expression in small cell lung cancer (Pedersen et al. 2006). A $0.7 \mathrm{~kb}$ promoter region from the ASCL1 gene was cloned by PCR using genomic DNA as template. Despite the use of a proofreading Taq polymerase sequencing of this short promoter region demonstrated 3 mismatches compared to the published sequence (Chen et al. 1997), 
thus demonstrating the high incidence of SNPs in noncoding regions. In addition we cloned a $1.7 \mathrm{~kb}$ promoter region from the INSM1 promoter originally cloned from a genomic library (Lan et al. 1994) into the Donor plasmid. Luciferase activities from both these promoters were also comparable to the conventionally cloned plasmids utilising 3 different cell lines, although demonstrating a consistent variation depending on cell lines and promotors used (Figure 3). This demonstrates that changing the backbone and/or introduction of a loxP site in the mRNA for some promoters and some cell lines can influence the activities up to $50 \%$. Therefore for deletion, insertion or mutation analyses of promoters it will be advisable to only use CreloxP cloned plasmids for direct comparisons of activities.

To expand the system for reporter genes, we generated Acceptor vectors with the genes encoding the reporter genes: the flourescent EGFP and DsRed and the enzyme $\beta$ galactosidase. The Acceptor vectors alone did not mediate expression of the reporter gene after transfection, whereas the EGFP and DsRed were highly expressed after recombination with the SV40 and INSM1 promoters (Figure 4a). No conventionally cloned plasmids were available for direct comparison. A Cre-loxP cloned plasmid using the SV40 Donor vector demonstrated the functionality of the $\beta$-galactosidase Acceptor plasmid (Figure 4b).

Finally, as our main interest is cloning, subcloning and improving promoters for use in transcriptionally targeted cancer gene therapy (Robson and Hirst, 2003; Pedersen et al. 2006), we generated an Acceptor vector with a commonly used suicide gene - HSVTK, which converts the non-toxic prodrug ganciclovir to a toxic substance leading to cell death (Fillat et al. 2003). For a high through-put screening, we have developed a simple transient transfection method to compare the therapeutic efficacies of promoters. This methods is much faster than the conventionally used viral transduction or stable transfection methods. However, using this method it is never possible to achieve $100 \%$ cell death, as only a fraction of the cells are transfected, but the method allows detection of relative efficiencies of promoters (Pedersen et al. 2006).

The method demonstrated that the Cre-loxP cloned plasmids resulted in levels of cell death equivalent to conventionally cloned plasmids after treatment with ganciclovir (Figure 5). For these plasmids we did not observe higher activity in the NCI H69 cell line, as is seen for luciferase This indicates that either the specific mRNA has an influence or does the distance from the loxP site to the translational initiation site (107 bp in the HSVTK constructs and $75 \mathrm{bp}$ in the luciferase constructs).

In this study designed for validation of the system, we used conventional cloning with restriction enzymes for insertion of the promoters into the Donor vectors. However, for cloning of novel, uncharacterised promoter regions, it would be highly advantageous to generate the promoter regions by PCR using DNA polymerases with high fidelities and which generate blunt ends (e.g. Pfu) followed by direct ligation into the Donor vector. Using this approach the entire cloning and subcloning can be performed in the total absence of restriction enzymes, which will greatly accelerate the entire process and allow for high throughput screenings. Subsequently promoter regions of interest can be sequenced for identification or verification. We find that the insertion of a $\operatorname{lox} P$ site and/or the change of backbone can to some degree influence the expression levels from the promoters. However, for high throughput screening purposes this can presumably be solved by only comparing activities of Cre-loxP cloned
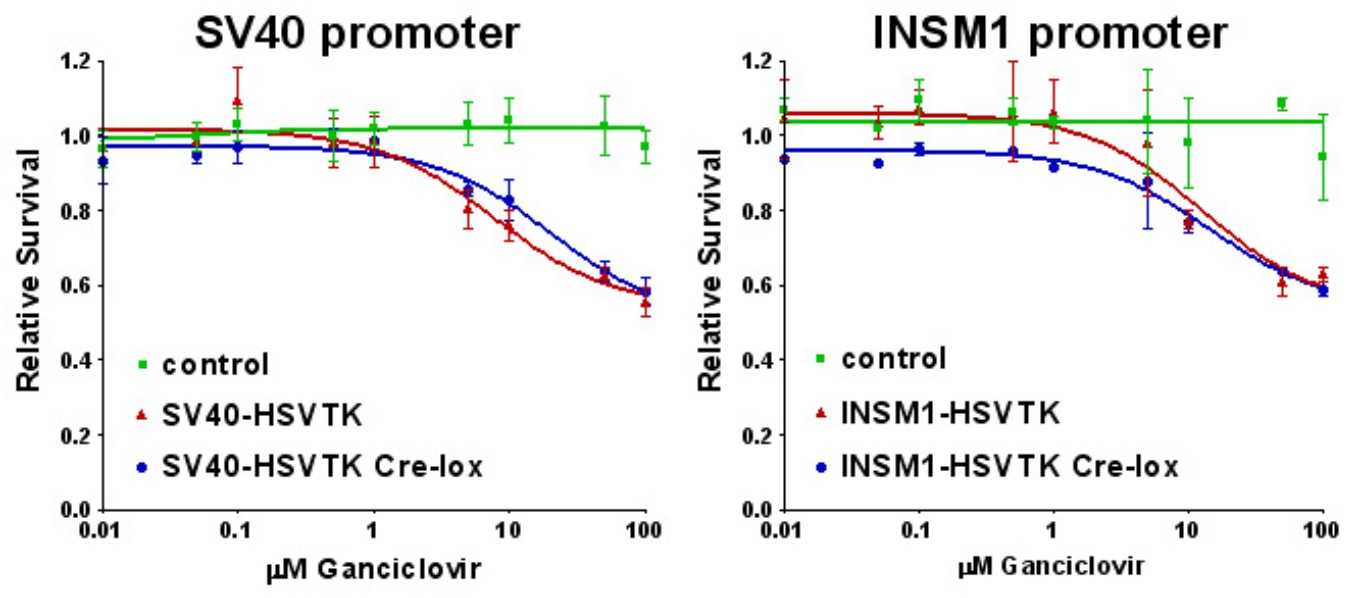

Figure 5. Expression of a therapeutic gene from conventionally and Cre-loxP cloned promoters and analysis of theraputic index. $\mathrm{NCl} \mathrm{H} 69$ cells were transiently transfected with the therapeutic gene HSVTK cloned by the conventional and Cre-loxP based method with the SV40 and INSM1 promoters. 24 hrs after transfection the cells were incubated with ganciclovir and cell survival was measured after 5 days. The control is a plasmid without HSVTK. The values for each plasmid is normalised to the samples without addition of ganciclovir (defined as a relative survival of 1). The data shown is mean of 2 (INSM1) or 4 (SV40) individual experiments with S.E.M. 
plasmids. For gene therapy purposes it is necessary to reclone the promoter and therapeutic gene into plasmids with $\mathrm{CpG}$ depleted backbones by conventional methods and the Cre-loxP introduced sequences can be removed in this process.

In this study we only tested plasmids used for transfection studies, but the method could easily be adapted for vectors for transgenic expression or viral vectors, thus further expanding the application of the system.

\section{REFERENCES}

BRESLIN, Mary B.; ZHU, Min and LAN, Michael S. NeuroD1/E47 regulates the E-box element of a novel zinc finger transcription factor, IA-1, in developing nervous system. Journal of Biological Chemistry, October 2003, vol. 278, no. 40, p. 38991-38997.

CHEN, Herber; BIEL, Margaret A.; BORGES, Michael W.; THIAGALINGAM, Arunthathi; NELKIN, Barry D.; BAYLIN, Stephen B. and BALL, Douglas W. Tissuespecific expression of human achaete-scute homologue-1 in neuroendocrine tumors: transcriptional regulation by dual inhibitory regions. Cell Growth and Differentiation, June 1997, vol. 8, no. 6, p. 677-686.

DUTTON, Gail. Cloning without restriction. The Scientist, September 2005, vol. 19, no. 17, p. 32-33.

FILLAT, C.; CARRIÓ, M.; CASCANTE, A. and SANGRO, B. Suicide gene therapy mediated by the herpes simplex virus thymidine kinase gene/ganciclovir system: fifteen years of application. Current Gene Therapy, February 2003, vol. 3, no. 1, p. 13-26.

HOESS, Ronald H. and ABREMSKI, Ken. Interaction of the bacteriophage $\mathrm{P} 1$ recombinase Cre with the recombining site loxP. Proceedings of the National Academy of Sciences of the United States of America, February 1984, vol. 81, no. 4, p. 1026-1029.

KNIGHT, Julian C. Functional implications of genetic variation in non-coding DNA for disease susceptibility and gene regulation. Clinical Science, May 2003, vol. 104, no. 5, p. 493-501.

LAN, Michael S.; LI, Qing; LU, Jia; MODI, William S. and NOTKINS, Abner L. Genomic organization, 5'-upstream sequence, and chromosomal localization of an insulinomaassociated intronless gene, IA-1. The Journal of Biological Chemistry, May 1994, vol. 269, no. 19, p. 14170-14174.

LIU, Qinghua; LI, Mamie Z.; LEIBHAM, Deborah; CORTEZ, David and ELLEDGE, Stephen J. The univector plasmid-fusion system, a method for rapid construction of recombinant DNA without restriction enzymes. Current Biology, December 1998, vol. 8, no. 24, p. 1300-1309.
PEDERSEN, Nina; MORTENSEN, Shila; SØRENSEN, Susanne B.; PEDERSEN, Mikkel W.; RIENECK, Klaus; BOVIN, Lone F. and POULSEN, Hans S. Transcriptional gene expression profiling of small cell lung cancer cells. Cancer Research, April 2003, vol. 63, no. 8, p. 1943-1953.

PEDERSEN, Nina; PEDERSEN, Mikkel W.; LAN, Michael S.; BRESLIN, Mary B. and POULSEN, Hans S. The insulinoma-associated 1: a novel promoter for targeted cancer gene therapy for small-cell lung cancer. Cancer Gene Therapy, April 2006, vol. 13, no. 4, p. 375-384.

ROBSON, Tracy and HIRST, David G. Transcriptional targeting in cancer gene therapy. Journal of Biomedicine and Biotechnology, 2003, vol. 2003, no. 2, p. 110-137.

SACHIDANANDAM, Ravi; WEISSMAN, David; SCHMIDT, Stephen C.; KAKOL, Jerzy M.; STEIN, Lincoln D.; MARTH, Gabor; SHERRY, Steve MULLIKIN, James C.; MORTIMORE, Beverly J.; WILLEY, David L.; HUNT, Sarah E.; COLE, Charlotte G.; COGGILL, Penny C.; RICE, Catherine M.; NING, Zemin; ROGERS, Jane; BENTLEY, David R.; KWOK, Pui Y.; MARDIS, Elaine R.; YEH, Raymond T.; SCHULTZ, Brian; COOK, Lisa; DAVENPORT, Ruth; DANTE, Michael; FULTON, Lucinda; HILLIER, LaDeana; WATERSTON, Robert H.; MCPHERSON, John D.; GILMAN, Brian; SCHAFFNER, Stephen; VAN ETTEN, William J.; REICH, David; HIGGINS, John; DALY, Mark J.; BLUMENSTIEL, Brendan; BALDWIN, Jennifer; STANGE-THOMANN, Nicole; ZODY, Michael C.; LINTON, Lauren; LANDER, Eric S. and ALTSHULER, David. A map of human genome sequence variation containing 1.42 million single nucleotide polymorphisms. Nature, February 2001, vol. 409, no. 6822, p. 928-933.

SAUER, Brian. Inducible gene targeting in mice using the Cre/lox system. Methods, April 1998, vol. 14, no. 4, p. 381392.

SHIGAKI, Toshiro; VYZASATYA, Ravindranadha R.; SIVITZ, Ali B.; WARD, John M.; SZE, Heven and HIRSCHI, Kendal D. The Cre-loxP recombination-based reporter system for plant transcriptional expression studies. Plant Molecular Biology, May 2005, vol. 58, no. 1, p. 6573. 